\title{
Identification of Meligethes matronalis and M. subaeneus based on morphometric and ecological characters (Coleoptera: Nitidulidae)*
}

\author{
Paolo AUdisio ${ }^{1}$, Carlo Belfiore ${ }^{2}$, Alessio DE BIASE ${ }^{1}$ and Gloria ANTONINI ${ }^{1}$ \\ ${ }^{1}$ Dipartimento di Biologia Animale e dell’Uomo, Università degli Studi di Roma "La Sapienza", Viale dell’Università 32, I-00185 \\ Rome, Italy; e-mail: paolo.audisio@uniroma1.it \\ ${ }^{2}$ Dipartimento di Zoologia, Università "Federico II" di Napoli, via Mezzocannone 8, I-80134 Naples, Italy
}

Key words. Coleoptera, Nitidulidae, Meligethes, taxonomy, Morphometric Discriminant Analysis, allozymes, host-plants

\begin{abstract}
An analysis of morphometric and bionomic data (as well as the genetic evidence discussed in a companion paper) clearly shows that Meligethes matronalis Audisio \& Spornraft, 1990 and M. subaeneus Sturm, 1845 (members of the Meligethes coracinus complex: Coleoptera, Nitidulidae, Meligethinae), recently synonymised by Kirejtshuk (1997), are distinct species. The two species are also compared with the closely related $M$. coracinus Sturm, 1845. Meligethes matronalis is strictly associated with Hesperis matronalis L. (Brassicaceae) in early Summer, whereas the larvae of the frequently syntopic M. subaeneus develop on Cardamine spp. (Brassicaceae) in Spring; M. coracinus is a more polyphagous species, developing from early Spring to late Summer mostly on Brassica spp., Sinapis spp., Barbarea spp. and Sisymbrium spp. (Brassicaceae).
\end{abstract}

\section{INTRODUCTION}

Meligethes Stephens, 1830 is the largest genus of the beetle family Nitidulidae, including in the Palaearctic Region some 250 pollen-eating species whose larval stages are associated with flowers of several plant families (mainly Brassicaceae, Fabaceae and Lamiaceae) (Kirejtshuk, 1992; Audisio, 1993b).

The large Palaearctic Meligethes aeneus-group contains several species complexes including some taxa that are very similar morphologically and difficult to classify (Audisio, 1993b; Audisio et al., 1999; Audisio \& De Biase, 1999).

The Meligethes coracinus complex includes $M$. coracinus Sturm, 1845 (Europe, Anatolia, Middle Asia, Siberia), M. subaeneus Sturm, 1845 (Europe), M. fulvipes C. Brisout de Barneville, 1863 (W Europe, W North Africa), M. longulus Schilsky, 1894 (Southern Europe, Anatolia, Caucasus), M. explanatus Reitter, 1900 (Middle Asia), and M. matronalis Audisio \& Spornraft, 1990 (Europe, Caucasus; Audisio \& Spornraft, 1990; Audisio, 1993 b), which has been recently synonymised with $M$. subaeneus by Kirejtshuk (1997). All the species, associated with members of the plant family Brassicaceae, characteristically have a submetallic dark brown to reddish body with yellowish to brown legs and antennae, and lack a bulge along the anterior edge of the fore femora and protruding teeth on the distal third of the posterior edge of the middle femora. With the exception of $M$. fulvipes and of $M$. explanatus, the species in the coracinus-complex have similar genitalia, making the morphological separation of these species difficult.

In order to clarify the taxonomy of this complex, we used a multimethod approach (comparison of allozymes and mtDNA sequences, morphometric analysis), and field observations on insect/host-plant relationships, phenology, and possible syntopic occurrence of two or more "species". The study was complicated by the many names have been published under Meligethes coracinus and its allies in the past and the present century, which has confused the nomenclature. In order to reduce the confusion we have reviewed the type material of all the taxa used in this study.

Despite the few interspecific morphological differences (which are frequently coupled with considerable intraspecific morphological variability), it is likely that other undescribed species are included in the taxa $M$. coracinus and $M$. longulus in Central and Southern Europe, and Asiatic Turkey (Audisio et al., 2000).

In this paper the specific difference between Meligethes matronalis and $M$. subaeneus are studied. This was based on a Morphometric Discriminant Analysis of samples from European populations of both taxa and of the closely related $M$. coracinus, and on field data on host-plant relationships, phenology, and syntopic occurrence.

Meligethes matronalis was described by Audisio \& Spornraft (1990) based on southern European specimens collected exclusively on the plant Hesperis matronalis L.; it differs from the closely related $M$. coracinus in the shape of its pronotum and aedeagus, and from $M$. subaeneus in having a shinier dorsal surface with coarser punctuation, and a more elongate aedeagus. Later Audisio (1993a, b) again reported this taxon as a separate species with some new country records, and other authors reported the species from Germany (Meybohm, 1995; Renner, 1995) and Denmark (Hansen et al., 1992, under M. subaeneus Sturm; Hansen et al., 1994). However,

\footnotetext{
* This study was supported by grants from MURST 1999 (University of "Roma Tre") "Variazione geografica e diversità a livello
} di specie, faune e zoocenosi: cause storiche ed ecologiche". 
Kirejtshuk (1997), ignoring the morphological differences and different host-plant preferences reported by other authors, proposed a new synonymy Meligethes matronalis Audisio \& Spornraft, $1990=$ M. subaeneus Sturm, 1845, and commented on the taxonomic situation as follows: "The forms regarded as subaeneus and matronalis (Audisio \& Spornraft, 1990) are scarcely distinguishable in their structures showing certain variability among specimens of large series from different parts of Southern Europe examined by the author in many collections, but the difference in host plants cannot give enough ground to divide them into two separate species, although the ranges of variability are slightly depending on ecological conditions".

In order to check the taxonomic status of these two Meligethes, we carried out morphometric and molecular analysis on a large number of specimens of the two taxa. Results of an allozyme analysis carried out on little less than 200 Italian specimens of $M$. subaeneus, $M$. matronalis and $M$. coracinus ( 3 species, 3 populations, 16 loci; Meligethes coracinus from Emilia, Mercato Saraceno (Forli); M. matronalis and M. subaeneus from Lazio, Rocca di Papa (Rome) ) are briefly reported below and more extensively discussed elsewhere (Audisio et al., in press).

\section{MATERIALS AND METHODS}

\section{Morphometric analysis}

Thirty adult male specimens belonging to three Meligethes taxa ( $M$. coracinus, $M$. subaeneus and $M$. matronalis) were collected from twenty-one localities in Central and Southern Europe and Turkey. Location of collecting sites and other details are listed in Table 1. Identification of each individual was based on external morphology (Audisio, 1993b). Only male specimens were chosen in order to more easily compare specimens using the same set of characters (including male genitalia). The analysis was based on a set of nine ratio characters and one angular measurement (listed in Table 2, and described in Fig. 1), that describe the morphometric interspecific variation within the species-complex.

The use of ratios has been criticised by some authors (Atchley et al., 1976), but supported by others who point out the value of using ratios to measure shape particularly when the raw data are logarithmically transformed (Hills, 1978; Dodson, 1978; Belfiore, 1996). In the present study numerical computations were performed on $\log _{10}(\mathrm{x})$ transformed characters (ratios).

Measurements of external body shape (pronotum and elytra) were made using a digital camera mounted on a MZ8 WILD stereomicroscope $(40-80 \mathrm{x})$, and the image processing software package WINVISION (Delta Sistemi, Rome). Measuremets of tarsal, antennal, and genital characters were all made using the

TABLE 1. Species and specimens examined along with details of locality, phenology and host plant.

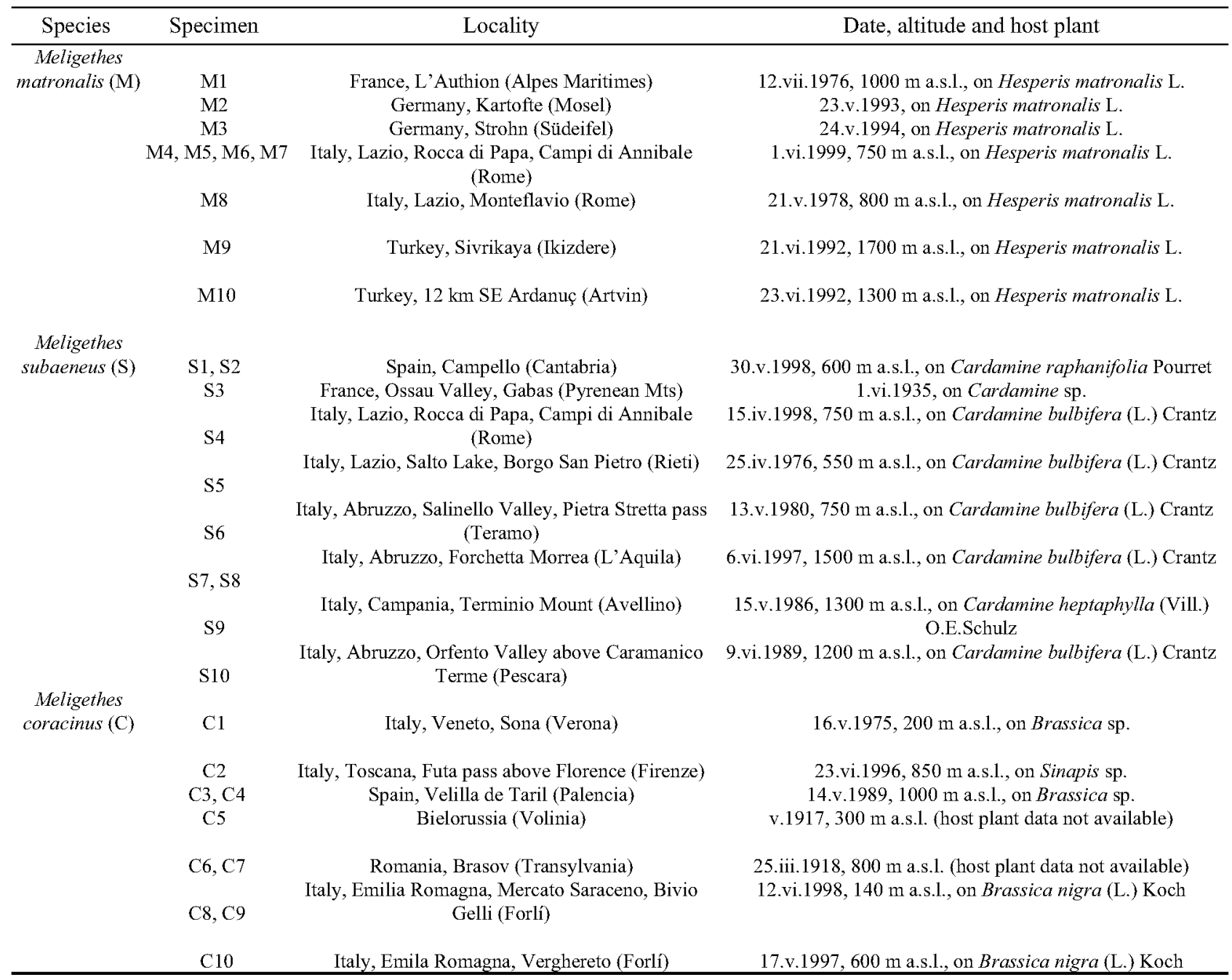



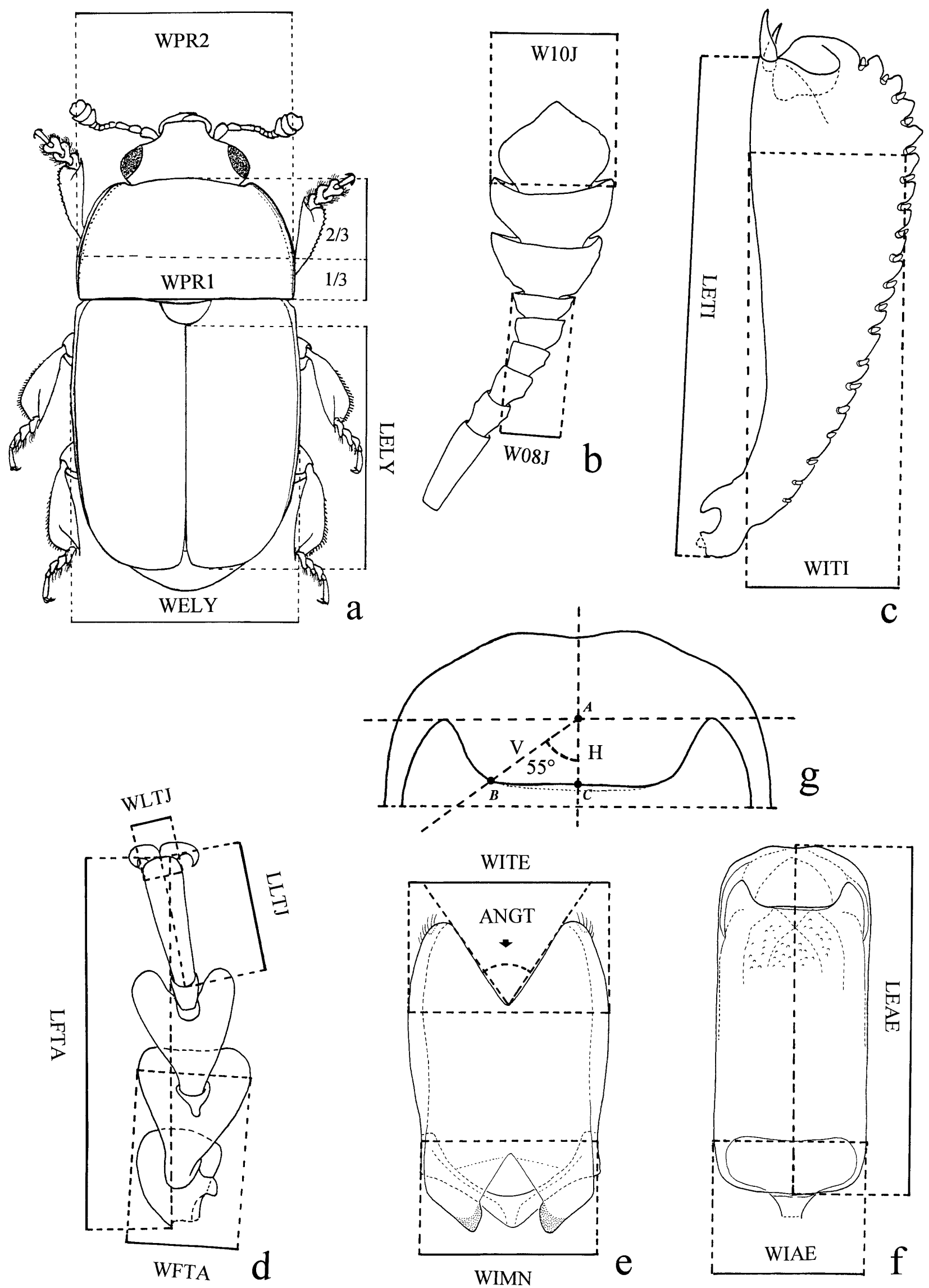

Fig. 1. Schematic drawings showing how morphological characters were measured on the Meligethes species. a: body shape and pronotum; b: antennae; c: front tibiae; d: front tarsi; e: tegmen; f: aedeagus; g: aedeagal apex. Refer to Table 2 for list of ratio characters and size acronyms. 


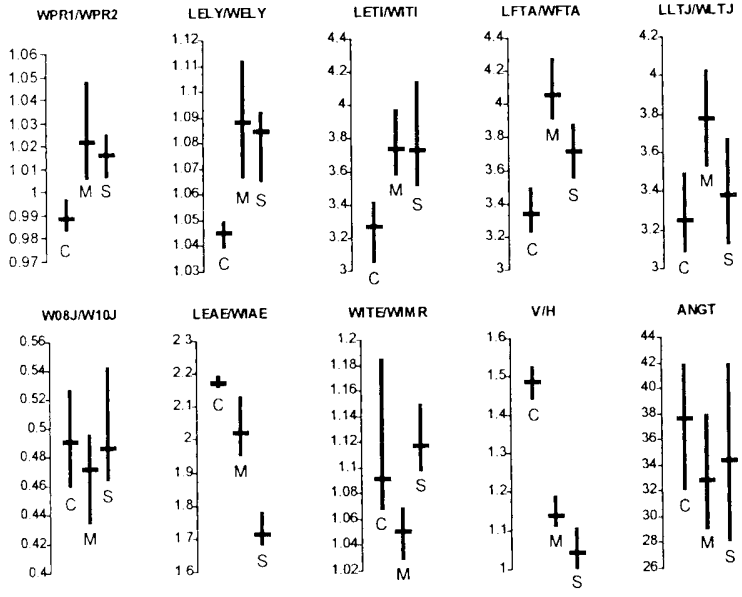

Fig. 2. Graphs of range and mean of each of the ten characters in the three species $(\mathrm{C}=$ Meligethes coracinus; $\mathrm{M}=M$. matronalis; $\mathrm{S}=M$. subaeneus $)$.

same device/software and from accurate drawings made with a drawing tube, both mounted on a BX50 OLYMPUS microscope $(200-1000 x)$. In the case of paired structures (e.g. legs, antennae or genital characters) the mean was used.

The following numerical analyses, using the methods described in Krzanowski (1990), were performed with the SPSS software package, version 8.0 (SPSS Inc., Chicago). Euclidean distances were computed between all pairs of specimens, after transformation of each character in the range $0-1$, a cluster

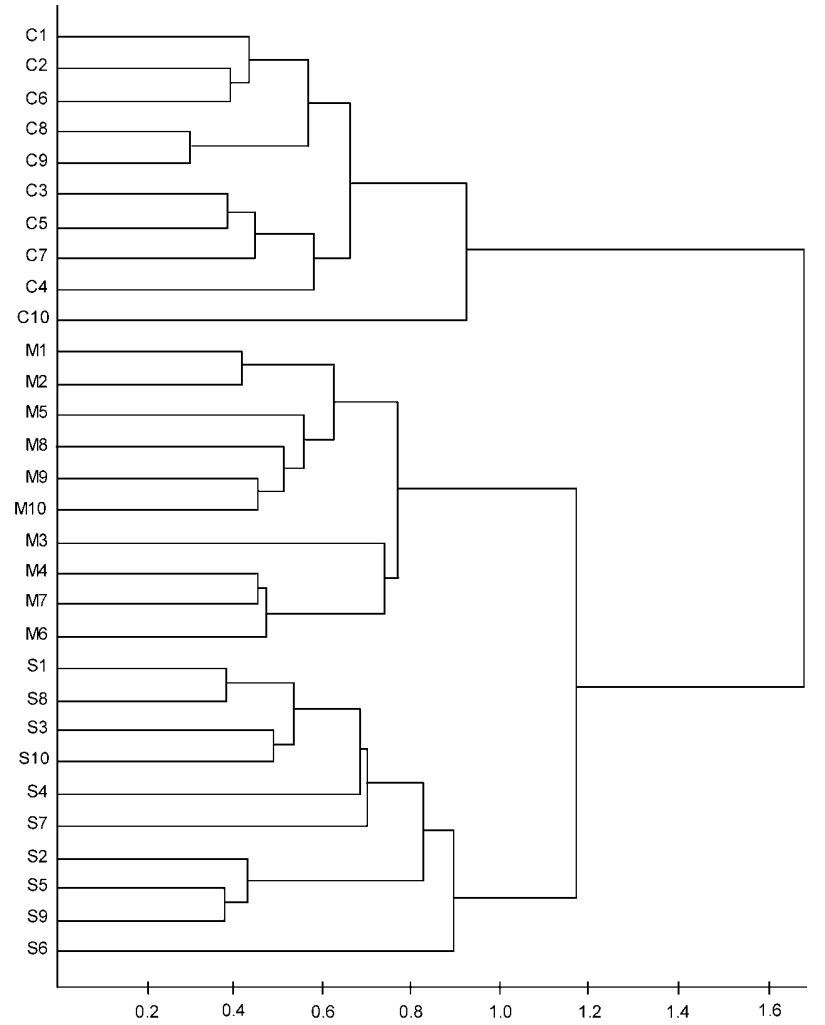

Fig. 3. UPGMA dendrogram of Euclidean distances between individuals $(\mathrm{C}=$ coracinus; $\mathrm{M}=$ matronalis; $\mathrm{S}=$ subaeneus; refer to Table 1 for specimen codes and localities). Cophenetic correlation $=0.96$. analysis was carried out using the UPGMA algorithm (Unweighted Pair-Group Method using Arithmetic average). The dendrogram was used to verify the specimens' clumping in homogeneous groups. A forward stepwise discriminant analysis of species differences was then performed (with the Wilks' Lambda criterion). With the stepwise method, characters are included one by one into analysis, and their discriminant power is evaluated: only characters whose contribution to discrimination is higher than a threshold value ( $\mathrm{F}$ to add $=3.84$, $F$ to remove $=2.71$ ) are accepted for the computation of final discriminant scores. The attribution of individuals to species was checked by computing the posterior probability of group membership based on the Mahalanobis distance from the respective centroids. This computation was made by cross-validation, i.e. applying to each individual the coefficients obtained from the analysis of all other individuals. Finally,

TABle 2. Definitions of the morphological features and ratio characters (see Fig. 1).

\begin{tabular}{|c|c|c|}
\hline & $\begin{array}{c}\text { measuremen } \\
\text { acronyms }\end{array}$ & measurement description \\
\hline SIZE1 & WPR1 & pronotal width at posterior angles (Fig. 1a) \\
\hline SIZE2 & WPR2 & pronotal width at $1 / 3$ of its length (Fig. 1a) \\
\hline SIZE3 & LELY & elytral length (mean) (Fig. 1a) \\
\hline SIZE4 & WELY & elytral width (mean) (Fig. 1a) \\
\hline SIZE5 & LETI & length of front tibiae (mean) (Fig. 1c) \\
\hline SIZE6 & WITI & $\begin{array}{l}\text { maximum width of front tibiae, excluding } \\
\text { teeth (mean) (Fig. 1c) }\end{array}$ \\
\hline SIZE7 & LFTA & total length of front tarsi (mean) (Fig. 1d) \\
\hline SIZE8 & WFTA & $\begin{array}{l}\text { maximum width of second tarsal joint of } \\
\text { front tarsi (mean) (Fig. 1d) }\end{array}$ \\
\hline SIZE9 & LLTJ & $\begin{array}{l}\text { length of last tarsal joint of front tarsi } \\
\text { (mean) (Fig. 1d) }\end{array}$ \\
\hline SIZE10 & WLTJ & $\begin{array}{l}\text { maximum width of last tarsal joint of front } \\
\text { tarsi (mean) (Fig. 1d) }\end{array}$ \\
\hline SIZE11 & W08J & $\begin{array}{l}\text { maximum width of } 8 \text { th antennal joint (Fig. } \\
\text { 1b) }\end{array}$ \\
\hline SIZE12 & W10J & $\begin{array}{l}\text { maximum width of } 10 \text { th antennal joint (Fig. } \\
\text { lb) }\end{array}$ \\
\hline SIZE13 & LEAE & length of aedeagus (Fig. 1f) \\
\hline SIZE14 & WIAE & maximum width of aedeagus (Fig. 1f) \\
\hline SIZE15 & WITE & maximum width of tegmen (Fig. 1e) \\
\hline SIZE16 & WIMN & $\begin{array}{l}\text { width of tegmen at subproximal narrowest } \\
\text { point (Fig. 1e) }\end{array}$ \\
\hline SIZE17 & $\mathbf{V}$ & $\begin{array}{l}\text { length of segment } \mathrm{AB} \text { in Fig. } 1 \mathrm{~g} \text { (apex of } \\
\text { aedeagus) }\end{array}$ \\
\hline SIZE18 & $\mathbf{H}$ & $\begin{array}{l}\text { length of segment } \mathrm{AC} \text { in Fig. 1g (apex of } \\
\text { aedeagus) }\end{array}$ \\
\hline \multirow[t]{12}{*}{ SIZE19 } & ANGT & $\begin{array}{l}\text { measure (expressed as ratio of the angular } \\
\text { value in degrees } \times 100 \text { over the value of } \\
180^{\circ} \text { ) of the sector defined by the inner } \\
\text { edges of the parameres (Fig. le) }\end{array}$ \\
\hline & $\begin{array}{l}\text { character } \\
\text { number }\end{array}$ & character acronyms \\
\hline & CHA1 & WPR1/WPR2 \\
\hline & CHA2 & LELY/WELY \\
\hline & CHA3 & LETI/WITI \\
\hline & CHA4 & LFTA/WFTA \\
\hline & CHA5 & LLTJ/WLTJ \\
\hline & CHA6 & W08J/W10J \\
\hline & CHA7 & LEAE/WIAE \\
\hline & CHA8 & WITE/WIMN \\
\hline & CHA9 & $\mathrm{V} / \mathrm{H}$ \\
\hline & CHA10 & ANGT \\
\hline
\end{tabular}


discriminant loading (correlation of characters with canonical variates) were computed to evaluate the contribution of each character to the discrimination of species.

\section{Phenology and host plants}

The field data of more than 400 adult specimens of $M$. subaeneus, nearly 600 specimens of $M$. matronalis, and more than 1400 of $M$. coracinus, collected by us or other colleagues in more than 70 European and Anatolian localities (Italy, France, northern Spain, Germany, Belgium, Norway, Denmark, Austria, Croatia, northern Greece and northern Turkey) in recent years are summarised. When possible, special attention was paid to collecting the larval stages, the sole proof of the existence of a strict insect/host-plant relationship.

\section{RESULTS}

\section{Morphometric analysis}

The values of the nine ratio characters and one angular size character (based on the 19 features listed in Table 2) in thirty specimens of Meligethes spp. are reported in Table 3 (see also Fig. 2).

The dendrogram (Fig. 3) constructed with UPGMA method using Euclidean distance values shows three clusters, which correspond well with the classification of the specimens based on traditional methods.

From the stepwise discriminant analysis four characters (V/H，LEAE/WIAE，LFTA/WFTA and LLTJ/WLTJ) were selected (see Table 5 for the threshold $\mathrm{F}$ values) for computing the canonical scores. All the specimens were correctly placed into species by discriminant analysis. The plot of individuals in the discriminant space (Fig. 4) shows that the three species are well separated. $M$. coracinus is widely separated from the other species along the first axis, $M$. subaeneus and $M$. matronalis are

TABLE 3. Values of the measured characters for specimens of Meligethes coracinus, $M$. matronalis and $M$. subaeneus (linear values expressed in micrometers; $\mathrm{C}=$ Meligethes coracinus; $\mathrm{M}=$ M. matronalis; $\mathrm{S}=$ M. subaeneus. Refer to Table 1 for specimen codes and localities).

\begin{tabular}{|c|c|c|c|c|c|c|c|c|c|c|}
\hline specimen & WPR1/WPR2 & LELY/WELY & LETI/WITI & LFTA/WFTA & LLTJ/WLTJ & W08J/W10J & LEAE/WIAE & WITE/WIMN & $\mathrm{V} / \mathrm{H}$ & ANGT \\
\hline $\mathrm{C} 1$ & 0.998 & 1.042 & 3.047 & 3.324 & 3.289 & 0.525 & 2.164 & 1.070 & 1.47 & 42 \\
\hline $\mathrm{C} 2$ & 0.992 & 1.048 & 3.255 & 3.360 & 3.205 & 0.496 & 2.179 & 1.109 & 1.50 & 42 \\
\hline $\mathrm{C} 3$ & 0.984 & 1.045 & 3.273 & 3.248 & 3.421 & 0.484 & 2.195 & 1.097 & 1.45 & 34 \\
\hline $\mathrm{C} 4$ & 0.988 & 1.044 & 3.251 & 3.373 & 3.268 & 0.527 & 2.168 & 1.075 & 1.52 & 33 \\
\hline $\mathrm{C} 5$ & 0.984 & 1.039 & 3.422 & 3.422 & 3.265 & 0.473 & 2.161 & 1.067 & 1.46 & 33 \\
\hline C6 & 0.992 & 1.041 & 3.201 & 3.225 & 3.500 & 0.507 & 2.181 & 1.105 & 1.50 & 42 \\
\hline $\mathrm{C} 7$ & 0.989 & 1.048 & 3.423 & 3.296 & 3.083 & 0.480 & 2.179 & 1.071 & 1.50 & 42 \\
\hline $\mathrm{C} 8$ & 0.983 & 1.050 & 3.270 & 3.389 & 3.343 & 0.459 & 2.165 & 1.074 & 1.50 & 38 \\
\hline C9 & 0.986 & 1.048 & 3.377 & 3.505 & 3.083 & 0.483 & 2.157 & 1.067 & 1.53 & 39 \\
\hline $\mathrm{C} 10$ & 0.993 & 1.047 & 3.190 & 3.310 & 3.079 & 0.475 & 2.161 & 1.185 & 1.44 & 32 \\
\hline mean & 0.989 & 1.045 & 3.271 & 3.345 & 3.254 & 0.491 & 2.171 & 1.092 & 1.49 & 37.7 \\
\hline M1 & 1.006 & 1.093 & 3.743 & 3.907 & 3.711 & 0.472 & 2.130 & 1.050 & 1.16 & 29 \\
\hline M2 & 1.028 & 1.087 & 3.576 & 3.914 & 3.528 & 0.434 & 1.953 & 1.063 & 1.15 & 30 \\
\hline M3 & 1.026 & 1.094 & 3.707 & 4.027 & 3.871 & 0.485 & 1.969 & 1.068 & 1.11 & 33 \\
\hline M4 & 1.048 & 1.089 & 3.675 & 4.178 & 3.676 & 0.478 & 2.132 & 1.046 & 1.12 & 38 \\
\hline M5 & 1.008 & 1.112 & 3.676 & 3.955 & 3.795 & 0.496 & 2.002 & 1.069 & 1.14 & 30 \\
\hline M6 & 1.029 & 1.066 & 3.676 & 4.190 & 4.028 & 0.465 & 1.984 & 1.044 & 1.19 & 33 \\
\hline M7 & 1.029 & 1.090 & 3.975 & 3.935 & 3.968 & 0.460 & 2.006 & 1.028 & 1.13 & 33 \\
\hline M8 & 1.015 & 1.088 & 3.963 & 4.277 & 3.737 & 0.453 & 2.019 & 1.044 & 1.18 & 36 \\
\hline M9 & 1.005 & 1.080 & 3.632 & 3.966 & 3.795 & 0.493 & 1.950 & 1.050 & 1.12 & 29 \\
\hline M10 & 1.024 & 1.085 & 3.789 & 4.238 & 3.632 & 0.486 & 2.060 & 1.049 & 1.11 & 38 \\
\hline mean & 1.022 & 1.088 & 3.741 & 4.059 & 3.774 & 0.472 & 2.021 & 1.051 & 1.14 & 32.3 \\
\hline $\mathrm{S} 1$ & 1.009 & 1.090 & 3.769 & 3.880 & 3.677 & 0.543 & 1.707 & 1.118 & 1.09 & 38 \\
\hline S2 & 1.021 & 1.091 & 3.569 & 3.548 & 3.472 & 0.479 & 1.680 & 1.101 & 1.11 & 39 \\
\hline S3 & 1.010 & 1.065 & 4.008 & 3.726 & 3.237 & 0.527 & 1.728 & 1.130 & 1.06 & 30 \\
\hline S4 & 1.025 & 1.090 & 3.598 & 3.868 & 3.400 & 0.464 & 1.783 & 1.110 & 1.05 & 42 \\
\hline S5 & 1.021 & 1.092 & 3.621 & 3.644 & 3.267 & 0.464 & 1.703 & 1.122 & 1.02 & 39 \\
\hline S6 & 1.018 & 1.089 & 3.709 & 3.713 & 3.290 & 0.486 & 1.718 & 1.150 & 1.02 & 31 \\
\hline S7 & 1.011 & 1.066 & 3.759 & 3.557 & 3.441 & 0.468 & 1.698 & 1.120 & 1.00 & 32 \\
\hline S8 & 1.021 & 1.092 & 3.511 & 3.813 & 3.412 & 0.493 & 1.699 & 1.114 & 1.05 & 33 \\
\hline S9 & 1.020 & 1.090 & 4.149 & 3.750 & 3.121 & 0.464 & 1.699 & 1.097 & 1.03 & 32 \\
\hline $\mathrm{S} 10$ & 1.006 & 1.085 & 3.612 & 3.636 & 3.528 & 0.479 & 1.747 & 1.108 & 1.02 & 28 \\
\hline mean & 1.016 & 1.085 & 3.731 & 3.714 & 3.385 & 0.487 & 1.716 & 1.117 & 1.05 & 34.4 \\
\hline
\end{tabular}




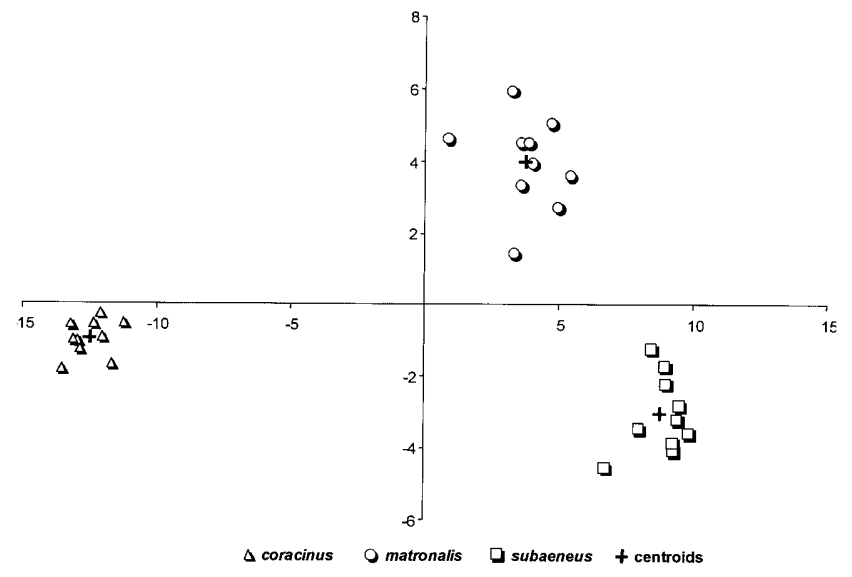

Fig. 4. Plot of specimens on the two canonical variates.

separated along the second axis. Analysing the discriminant loading, $\mathrm{V} / \mathrm{H}$ has the highest correlation with the first canonical variate $(-0.633)$ followed by LEAE/WIAE (-0.447) and LFTA/WFTA (0.212). Along the second axis LEAE/WIAE has the highest correlation (0.732), followed by LFTA/WFTA (0.566) and LLTJ/WLTJ (0.413).

\section{Phenology and host plants}

Larval stages of the two taxa were only found on Cardamine spp. (M. subaeneus) and on Hesperis matronalis L. ( $M$. matronalis), which confirms the observations of Audisio \& Spornraft (1990). We recorded localities where the two taxa (and the closely related $M$. coracinus, mostly collected on Brassica spp., Sinapis spp., Barbarea spp. and Sisymbrium spp. (Brassicaceae))

TABLE 4. List of European and Turkish localities where Meligethes subaeneus, Meligethes matronalis and Meligethes coracinus coexist.

\begin{tabular}{cl}
\hline \multicolumn{2}{c}{ Meligethes subaeneus x Meligethes matronalis } \\
1 & France, L'Authion (Alpes Maritimes) \\
2 & Italy, Lama Forest above Forli (Emilia Romagna) \\
3 & Italy, Rocca di Papa in the vicinity of Rome (Lazio) \\
4 & Italy, Monteflavio in the vicinity of Rome (Lazio) \\
5 & Italy, Terminio Mount in the vicinity of Avellino (Campania) \\
6 & Hungary, Nagybérk \\
& Meligethes coracinus x Meligethes subaeneus \\
1 & France, L'Authion (Alpes Maritimes) \\
2 & Italy, Lama Forest above Forli (Emilia Romagna) \\
7 & Spain, La Vega (Cantabria) \\
8 & Spain, Velilla de Taril (Palencia) \\
9 & Italy, Futa Pass above Florence (Toscana) \\
10 & Norway, Snarøya in the vicinity of Oslo \\
11 & Czech Republic, Zdice (Bohemia) \\
12 & Hungary, Budapest \\
& Meligethes coracinus x Meligethes matronalis \\
1 & France, L'Authion (Alpes Maritimes) \\
2 & Italy, Lama Forest above Forli (Emilia Romagna) \\
13 & Germany, Penzberg (Bayern) \\
14 & Hungary, Bukki National Park \\
15 & Czech Republic, Pruhonice (Bohemia) \\
16 & Czech Republic, Castolovice (Bohemia) \\
17 & Turkey, forest in the vicinity of Ardanuç (Artvin) \\
\hline
\end{tabular}

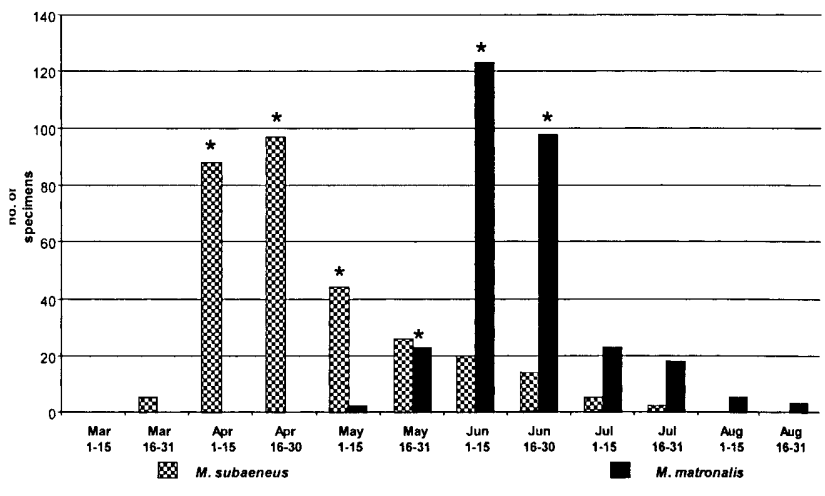

Fig. 5. Histograms of the phenology of Meligethes subaeneus and M. matronalis (years 1998/1999) in a locality where they coexist (Italy, Rocca di Papa in the vicinity of Rome (Lazio), Campi di Annibale, $750 \mathrm{~m}$ a.s.1.); stars indicate that specimens were collected on their larval host-plant. Samples (approximately 30' sweeps with a net in an area of $100 \times 100 \mathrm{~m}$ of copse Chestnut forest) were collected fortnightly from March to September.

occured syntopically (Table 4). Moreover, in a locality in the vicinity of Rome, the phenology of both taxa in different years (1998/1999), was observed, which revealed a clear-cut difference in resource exploitation. M. subaeneus usually appeared between late March and early April, and disappeared by late May/early June, while $M$. matronalis usually appeared in late May, and disappeared by late July/early August (Fig. 5). In the sole Italian locality studied where all three species coexisted (Emilia-Romagna, Foresta della Lama (Forli), $800 \mathrm{~m}$ a.s.l.; observed in spring and summer 1990 and 1998), $M$. coracinus appeared from late April to late August, $M$. matronalis from early June to late July, and M. subaeneus from late April to early June.

\section{CONCLUDING REMARKS}

Coupled with the phenology and host plant relations, and the data from the allozyme analysis (Audisio et al., in press a), this morphometric study gives further evidence of a clear-cut specific distinction between $M$. matronalis and M. subaeneus, and clearly shows that Kirejtshuk (1997) was wrong. Despite the overlap in some of the morphological characters in these three species (Table 3; Fig. 2), other characters distinguish at least one species. The V/H, LEAE/WIAE and LFTA/WFTA characters clearly discriminate $M$. coracinus from $M$. matronalis and subaenes, while LEAE/WIAE, LFTA/WFTA and LLTJ/WLTJ separate M. matronalis and subaeneus.

TABLE 5. F values used for removing characters in the stepwise discriminant analysis.

\begin{tabular}{ccc}
\hline Step & Character & F to enter/remove \\
\hline 1 & V/H & 484.0081 \\
2 & LEAE/WIAE & 77.7377 \\
3 & LFTA/WFTA & 19.2417 \\
4 & LLTJ/WLTJ & 5.9096 \\
\hline
\end{tabular}




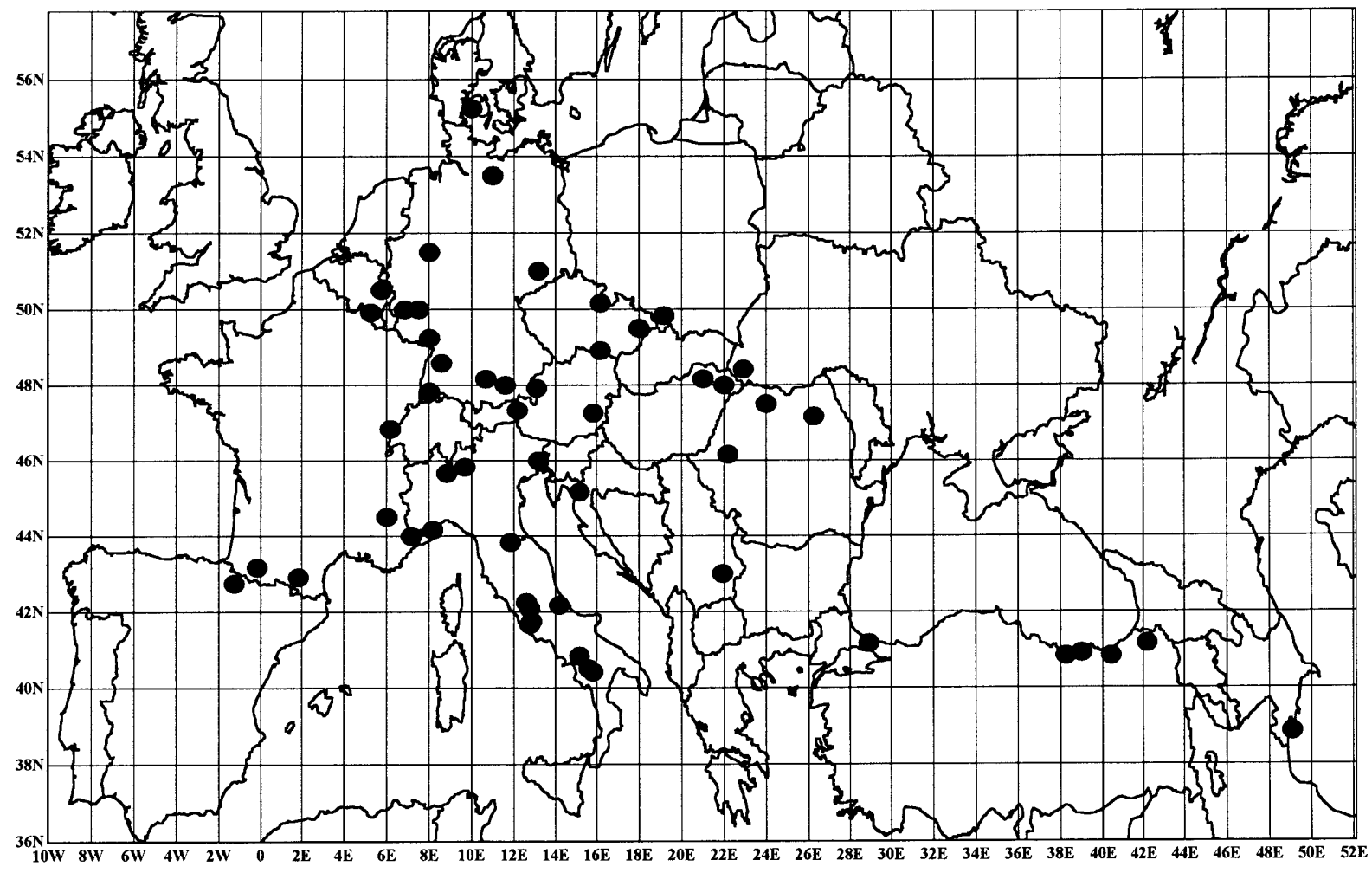

Fig. 6. Geographic distribution of Meligethes matronalis.

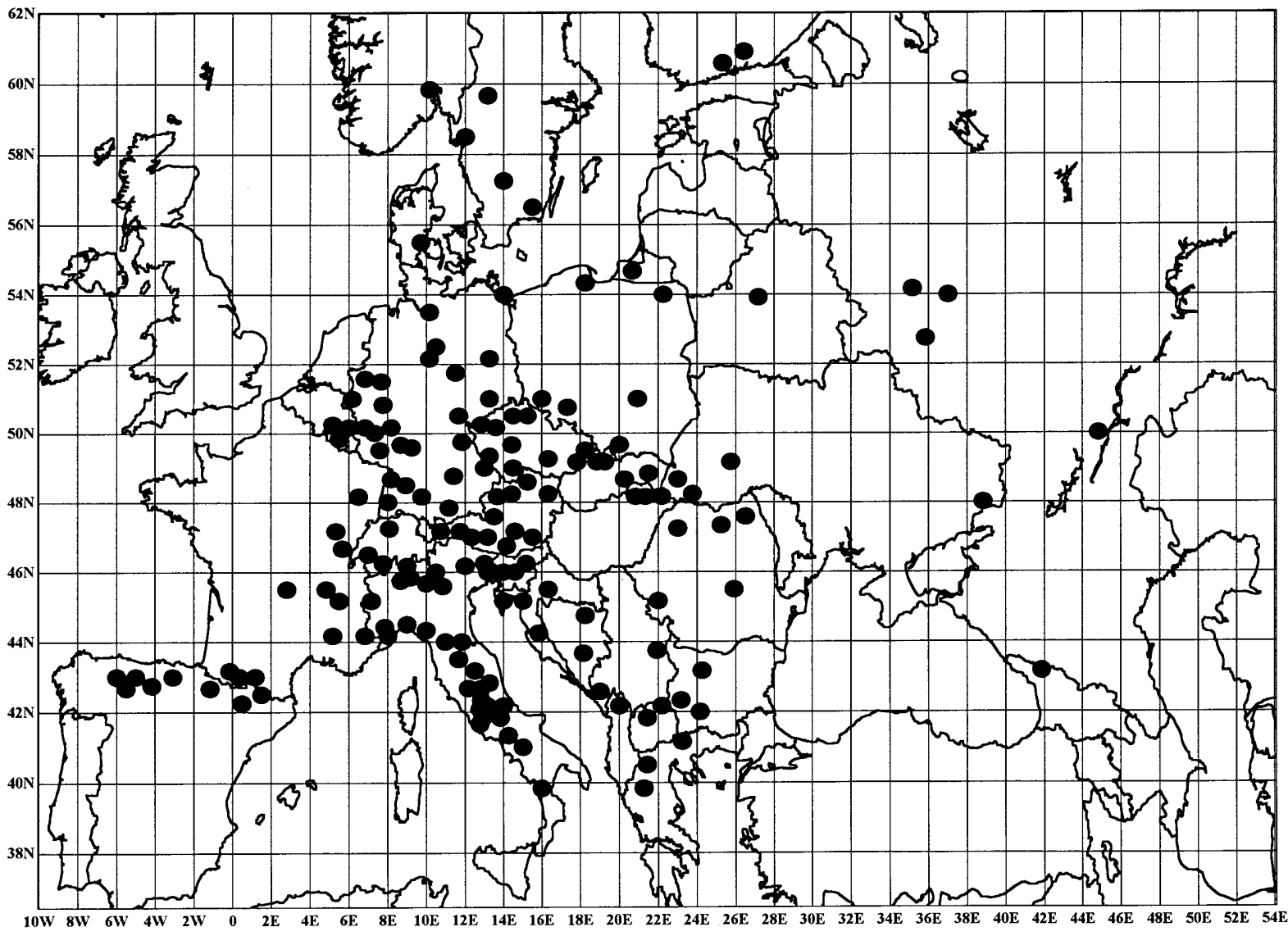

Fig. 7. Geographic distribution of Meligethes subaeneus. 

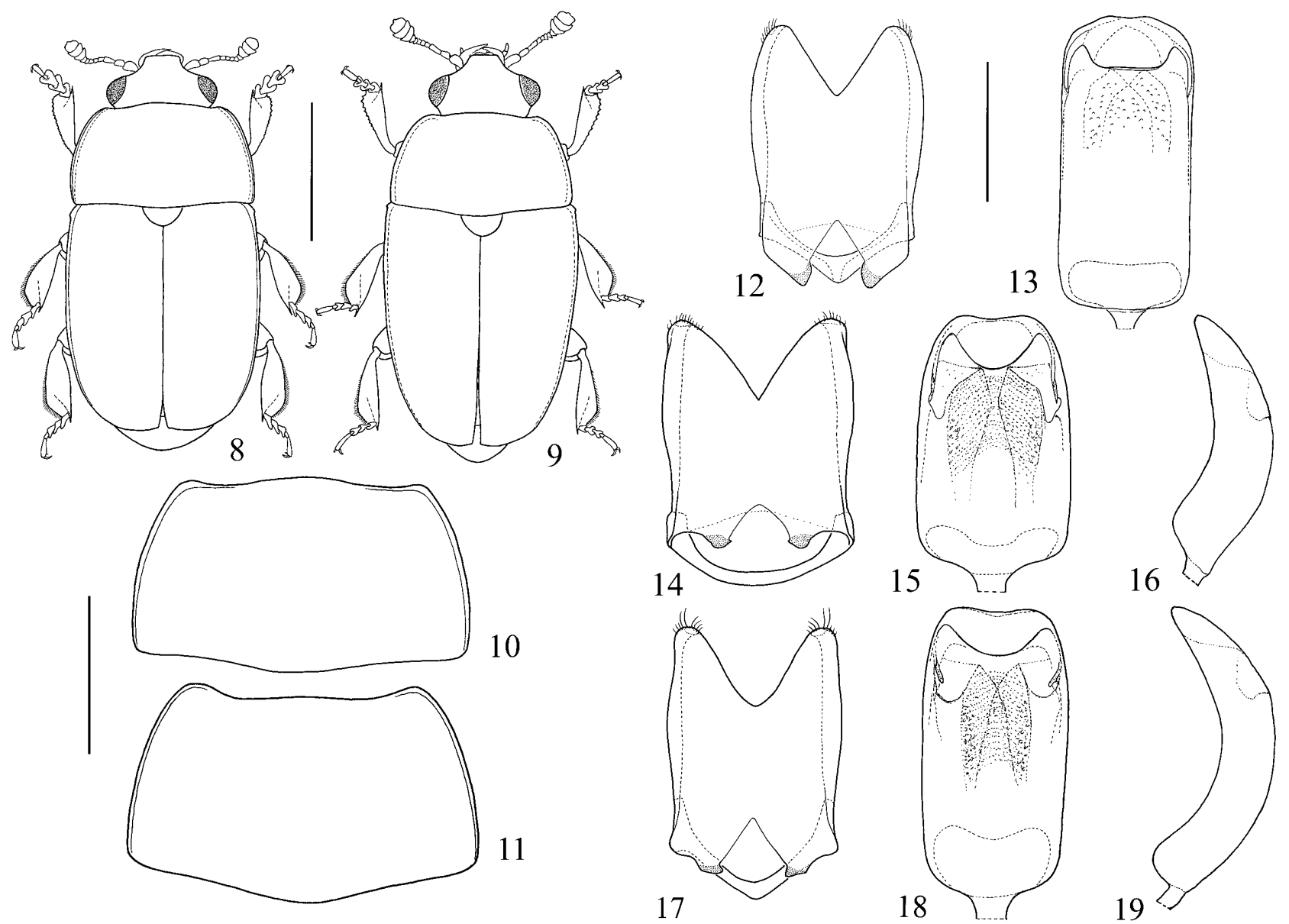

Figs 8-19: 8 - Body outline of Meligethes coracinus, male specimen from Italy, Lombardia, Lovero Valtellino; 9 - and of Meligethes matronalis, male specimen from Italy, Lazio, Rocca di Papa; 10 - outline of the pronotum of $M$. coracinus, male specimen from Italy, Lombardia, Lovero Valtellino; 11 - and of M. matronalis, male specimen from Italy, Lazio, Rocca di Papa; 12-13 Tegmen and median lobe of the aedeagus (dorsal view) of $M$. coracinus, male specimen from Italy, Lombardia, Lovero Valtellino; 14-16 Tegmen and median lobe of the aedeagus (the latter in dorsal and lateral view) of Meligethes subaeneus, male specimen from Italy, Lazio, Rocca di Papa; 17-19 and of M. matronalis, male specimen from Italy, Lazio, Rocca di Papa. Scale barvive: $8-9=1 \mathrm{~mm} ; 10-11=0.7 \mathrm{~mm} ; 12-19=0.19 \mathrm{~mm}$.

As reported in Audisio et al. (in press) the Nei's genetic distance (1978), suggests an estimated value of $\mathrm{D}=0.504$ between M. matronalis and subaeneus, and $\mathrm{D}=0.572$ between M. coracinus and subaeneus. However, the low numeric value of the estimated genetic distance between M. coracinus and matronalis $(\mathrm{D}=0.198)$ is rather surprising, and contradicts the evidence of the morphological analysis (including the shape of the male and female genitalia), which clearly suggests a closer phenetic relationship between matronalis and subaeneus than between matronalis and coracinus. We are working on a cladistic analysis based on mtDNA sequence data, which includes all the other species of the complex, in order to obtain a better understanding of the phylogenetic and evolutionary relationships within the group.

The distributions of both $M$. matronalis and $M$. subaeneus are reported in Figs 6, 7.

The three taxa can be identified using the following key.

\section{KEY FOR THE IDENTIFICATION OF MELIGETHES CORACINUS, M. MATRONALIS AND M. SUBAENEUS}

1 (2) Male front tarsi wider [ratio LFTA/WFTA (Fig. 1d ) = 3.23-3.50; Figs 8, 31]; male front tibiae comparatively wider and shorter [ratio LETI/WITI (Fig. 1c ) =3.05-3.42; Figs 8,34$]$; maximum pronotal width usually at posterior third (Figs 8,10), and ratio WPR1/WPR2 (Fig. 1a) less than 1.00. Aedeagal ostium with very wide and widely truncate, well-sclerotised proximal edge (Figs 13, 20), with V/H ratio (Fig. 1g) more than 1.4, and aedeagal apex differently shaped. Ovipositor with wider, more obtuse, and distinctly darkened apex (Figs 22, 25). Larval stages found mainly on Brassica spp., Sinapis spp., and Sisymbrium spp. Euro-Siberian species, distributed from northern Spain to eastern Siberia. ........... coracinus Sturm, 1845

2 (1) Male front tarsi narrower [ratio LFTA/WFTA (Fig. 1d) = 3.55-4.28; Figs 9, 32-33]; male front tibiae comparatively narrower and longer [ratio LETI/WITI (Fig. 1c ) $=3.51-4.15 ;$ Figs 9, 35-36]; maximum pronotal width usually at posterior angles (Figs 9, 11), and ratio WPR1/WPR2 (Fig. 1a) more than 1.00. Aedeagal ostium with narrower and less widely U-shaped, barely sclerotised 

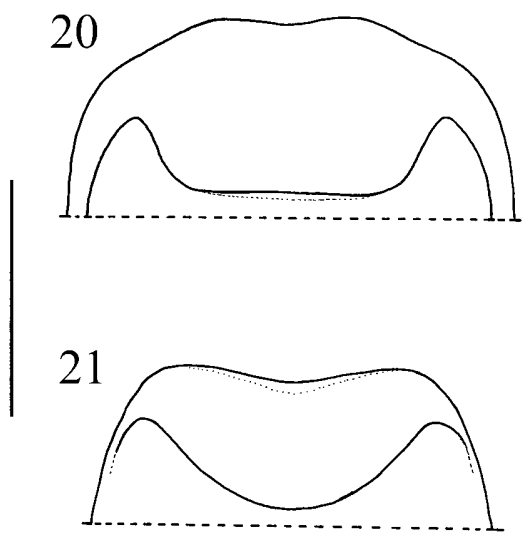
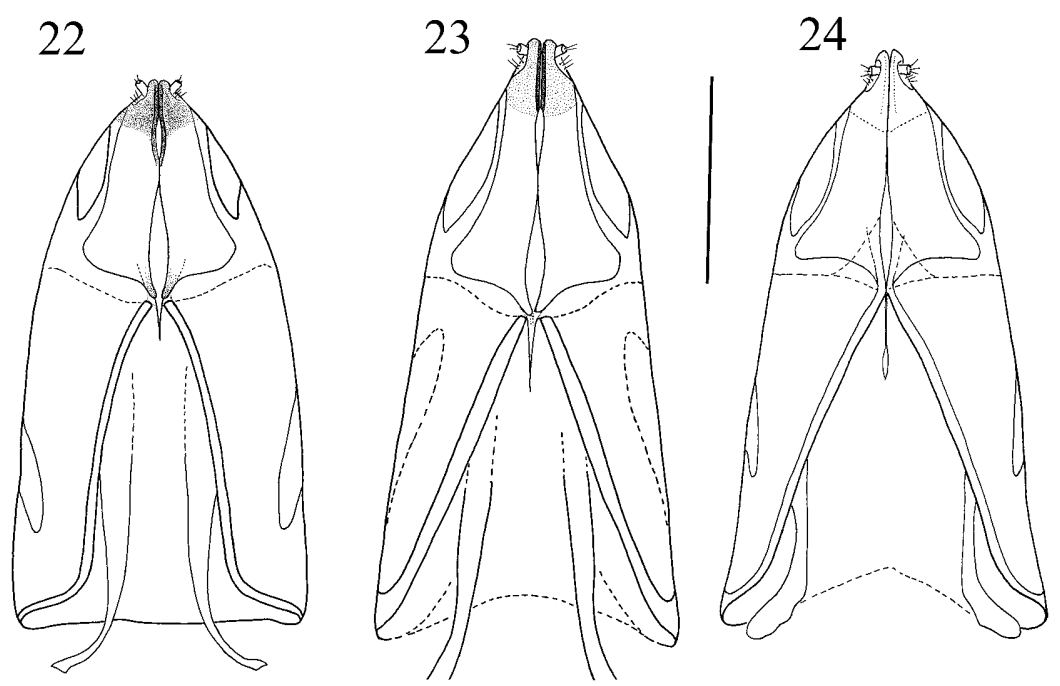

Figs 20-24: 20 - Apex of the aedeagus, showing proximal edge of the ostium, of Meligethes coracinus, male specimen from Italy, Lombardia, Lovero Valtellino; 21 - and of $M$. matronalis, male specimen from Italy, Lazio, Rocca di Papa; 22 - Ovipositors of $M$. coracinus, female specimen from Italy, Lombardia, Lovero Valtellino; 23 - of M. matronalis, female specimen from Italy, Lazio, Rocca di Papa; 24 - and of M. subaeneus, female specimen from Italy, Lazio, Rocca di Papa. Scale bars: $20-21=0.09 \mathrm{~mm}$; $22-24=0.19 \mathrm{~mm}$

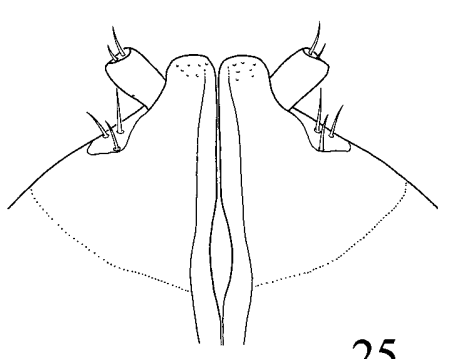

25
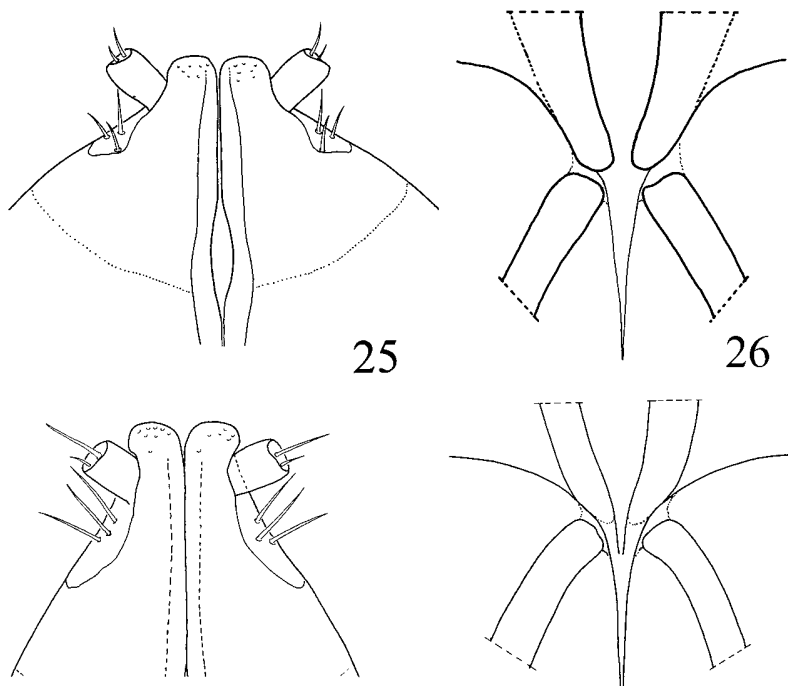

27
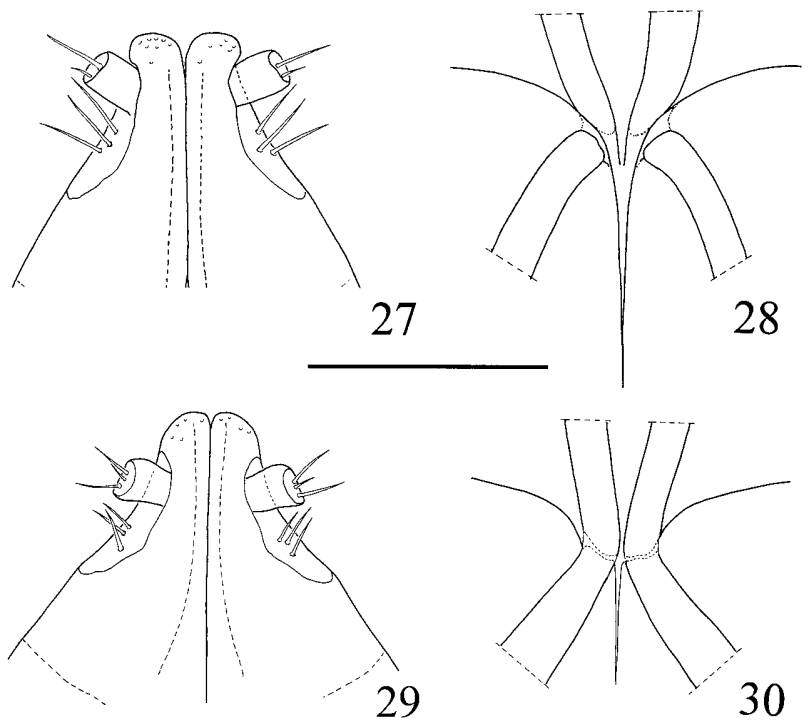

Figs 25-30: 25-26 Apex and "central point" of the ovipositor of Meligethes coracinus, female specimen from Italy, Lombardia, Lovero Valtellino; 27-28 of M. matronalis, female specimen from Italy, Lazio, Rocca di Papa; 29-30 and of $M$. subaeneus, female specimen from Italy, Lazio, Rocca di Papa. Scale bar $=0.09 \mathrm{~mm}$.

proximal edge (Figs 15, 18, 21), with $\mathrm{V} / \mathrm{H}$ ratio (Fig. 1g) less than 1.2 , and aedeagal apex differently shaped. Ovipositor with narrower, more acute, and not darkened or slightly darkened apex (Figs 23-24, 27, 29). . . . . . . . . 3

3 (4) Aedeagus more elongate, with ratio LEAE/WIAE (Fig. 1f)

$=1.95-2.13$ (Fig.18), and proximal edge of aedeagal ostium on average less deeply arcuate $[\mathrm{V} / \mathrm{H}$ ratio (Fig. $1 \mathrm{~g}$ ) = 1.11-1.19]. Male front tarsi narrower [ratio LFTA/WFTA (Fig. 1d) = 3.91-4.28; Fig. 32], with last joint on average more elongate. Dorsal surface (especially on pronotum) usually more shiny, and with slightly coarser and more deeply impressed punctures (Fig. 37). Ovipositor with slightly darkened apex (Fig. 23) and with proximal parts of inner marginal sclerites of coxites and valvifers not fused at "central point" (Fig. 28). Larval stages found only on Hesperis matronalis L. Euro-Anatolian species, distributed from northern Spain to northern Pontic Chain and Azerbaijan (Fig. 6) . . . . . . . . . . . . . . . . . . ........... matronalis Audisio \& Spornraft, 1990

4 (3) Aedeagus less elongate, with ratio LEAE/WIAE (Fig. 1f) $=1.68-1.78$ (Fig. 15), and proximal edge of aedeagal ostium on average more deeply arcuate $[\mathrm{V} / \mathrm{H}$ ratio (Fig. $1 \mathrm{~g}$ ) $=$ 1.00-1.11]. Male front tarsi wider [ratio LFTA/WFTA (Fig. $1 \mathrm{~d})=3.55-3.88$; Fig. 33], with last joint on average shorter. Dorsal surface (especially on pronotum) usually duller, and with slightly finer, and less deeply impressed punctures (Fig. 38). Ovipositor lacks darkened apex (Fig. 24) and has proximal parts of inner marginal sclerites of coxites and valvifers partly apparently fused at "central point" (Fig. 30). Larval stages found on Cardamine spp. Euro-Caucasian species, distributed from northern Spain to northern Caucasus (Fig. 7). . . . . . . . . . subaeneus Sturm, 1845

ACKNOWLEDGEMENTS. We are indebted to J. Jelínek (National Museum, Prague), K. Spornraft (Penzberg), K. Renner (Bielefeld), O. Merkl (National Museum of Natural History, Budapest), M. Jäch (Natural History Museum, Vienna) and E. Sprecher (Natural History Museum, Basel) for providing us with important comparative material of Meligethes spp. from Central Europe and the Near East. We also thank N. Falchi (Rome) for help in preparing some of the line drawings, and J. Rohlf (Stony Brook University, New York) for valuable comments on early drafts of the paper. 

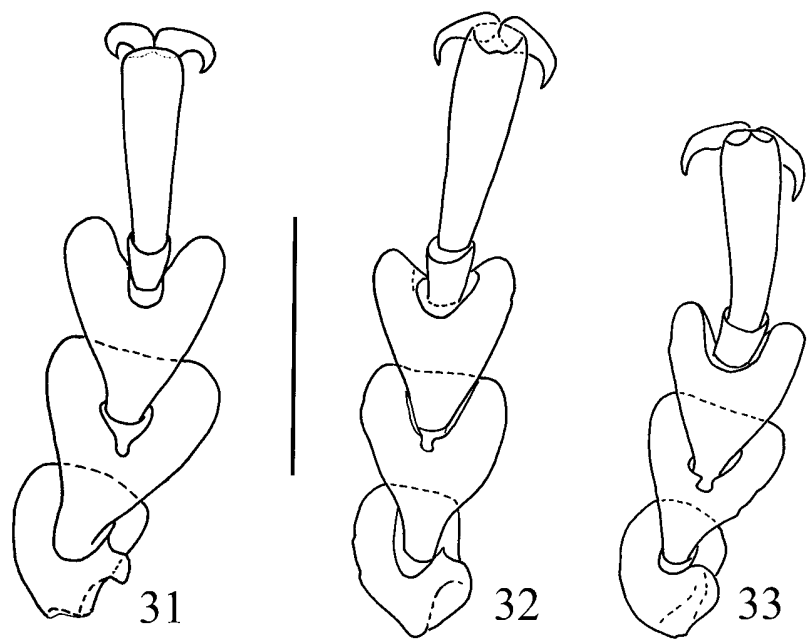

Figs 31-33: 31 - male front tarsi of $M$. coracinus, male specimen from Italy, Lombardia, Lovero Valtellino; 32 - of $M$. matronalis, male specimen from Italy, Lazio, Rocca di Papa; 33 - and of M. subaeneus, male specimen from Italy, Lazio, Rocca di Papa. Scale bar $=0.09 \mathrm{~mm}$.

Figs 34-36: 34 - Front tibiae of male Meligethes coracinus, male specimen from Italy, Lombardia, Lovero Valtellino; 35 M. matronalis, male specimen from Italy, Lazio, Rocca di Papa; 36 - and M. subaeneus, male specimen from Italy, Lazio, Rocca di Papa. Scale bar $=0.19 \mathrm{~mm}$.

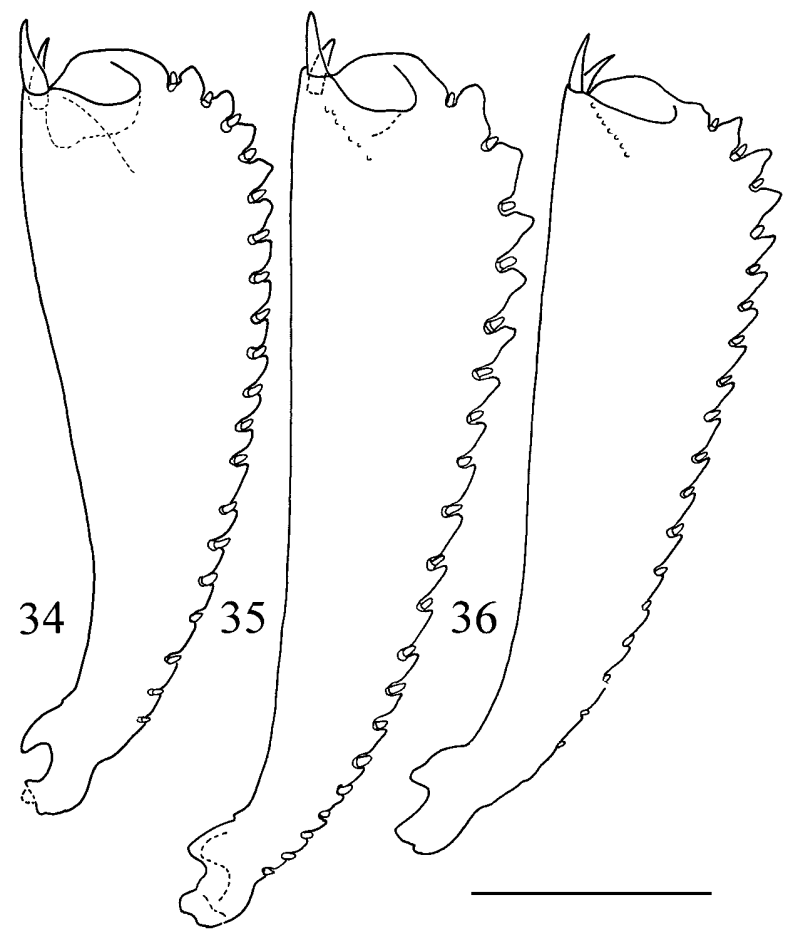

\section{REFERENCES}

Atchley W.R., Gaskin C.T. \& Anderson D. 1976: Statistical properties of ratios. I. Empirical results. Syst. Zool. 25: 137-148.

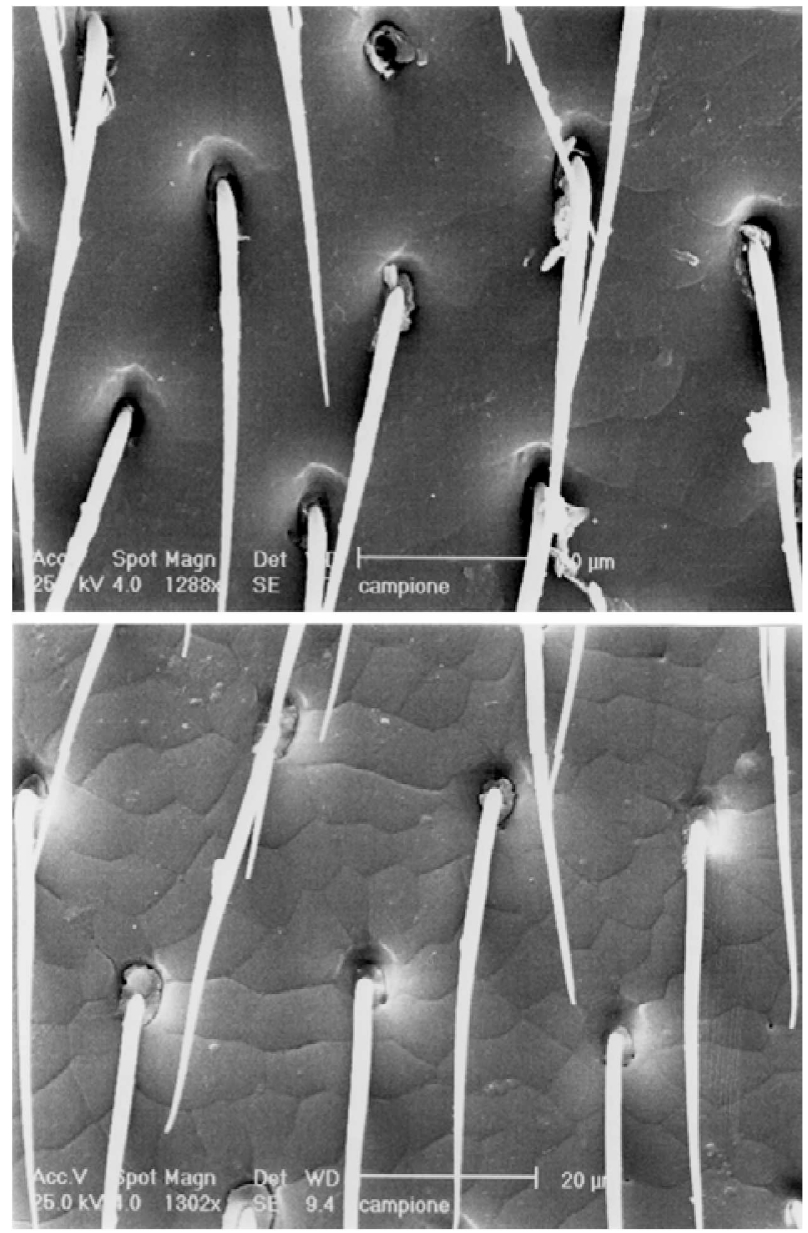

Figs. 37-38: 37 - SEM discal surface of the pronotum of $M$. matronalis; 38 - and $M$. subaeneus.

Audisio P. 1993a: Nuovi dati faunistici e bionomici sui Meligethes di Turchia orientale, con descrizione di una nuova specie del gruppo di M. difficilis (Coleoptera, Nitidulidae, Meligethinae). Fragm. Entomol. 24 : 181-193.

Audisio P. 1993b: Coleoptera Nitidulidae, Kateretidae. Fauna d'Italia 32, Calderini, Bologna, $971 \mathrm{pp}$.

Audisio P. \& De Biase A. 1999: Bionomic and morphological evidence of a new southern European species of the Meligethes viridescens complex (Coleoptera: Nitidulidae). Folia Heyrovskyana 7: 99-113.

Audisio P., De Biase A., Romanelli P., Angelici M.C., Ketmaier V. \& De Matthaeis E. 1999: Molecular re-examination of the taxonomy of the Meligethes viridescens species complex (Coleoptera: Nitidulidae). Biochem. Syst. \& Ecol. 28: 1-13.

Audisio P., Jelínek J., Mariotti A. \& De Biase A. 2000: The Coleoptera Nitidulidae and Kateretidae from Anatolian, Caucasian and Middle East regions. Biogeographia, Lav. Soc. It. Biogeogr. 21: 241-354.

Audisio P., De Biase A., Antonini G., Oliverio M., Ketmaier V. \& De Matthaeis E.: Specific distinction by allozymic data of two sympatric species of phytophagous beetles (Coleoptera: Nitidulidae). Biochem. Syst. \& Ecol. 28, in press

Audisio P. \& Spornraft K. 1990: Taxonomie, Ökologie und Verbreitung von Meligethes coracinus auctt. mit Beschreibung einer neuen Art (Coleoptera: Nitidulidae). 
NachrBl. Bayer. Entomol. 39: 70-75.

BelfioRE C. 1996: Identification and discrimination of Electrogena species by numerical methods (Ephemeroptera: Heptageniidae). Syst. Entomol. 21: 1-13.

Dodson P. 1978: On the use of ratios in growth studies. Syst. Zool. 27: 62-67.

Hansen M., Kristensen S., Mahler V. \& Pedersen J. 1992: 11 tillaeg til "Fortegnelse over Danmarks biller" (Coleoptera). Entomol. Medd. 60: 69-84 (in Danish).

Hansen M., Mahler V., Pritzl G. \& Runge G.B. 1994: 13 tillaeg til "Fortegnelse over Danmarks biller" (Coleoptera). Entomol. Meddr. 62: 65-89 (in Danish).

Hricls M. 1978: On ratios - a response to Atchley, Gaskins, and Anderson. Syst. Zool. 27: 61-62.

KIREJTSHUK A.G. 1992: Nitidulidae, Kateretidae. In Ler P.A. (ed.): Key to Insects of the Far East of the USSR, Vol. 3, Coleoptera, part 2. Nauka, St. Petersburg, pp. 114-216 (in
Russian).

KrReJTshur A.G. 1997: New Palaearctic nitidulid beetles, with notes on synonymy and systematic position of some species (Coleoptera: Nitidulidae). Zoosyst. Rossica 6: 255-268.

KRZANowsKI W.J. 1990: Principles of Multivariate Analysis: a user's Perspective. Clarendon Press, Oxford, 563 pp.

Меувонм Н. 1995: Meldungen zur Käferfauna von Schleswig-Holstein, Hamburg und Nord-Niedersachsen. II.Teil. Bombus (Hamburg) 3: 49-50.

NeI M. 1978: Estimation of average heterozygosity and genetic distance from a small number of individuals. Genetics $\mathbf{8 9}$ : 583-590.

ReNNER K. 1995: Meligethes reitteri Schilsky und Meligethes matronalis Audisio \& Spornraft im westlichen Deutschland (Col.,Nitidulidae). Mitt. ArbGem. Rhein. Koleopt. (Bonn) 5: 195-197.

Received February 7; accepted May 4, 2000 